\title{
A Study of EFL Learners' Oral English Development in Light of Dynamic Systems Theory*
}

\author{
Juan Zuo \\ Foreign Language School \\ Wuchang Shouyi University \\ Wuhan, China
}

\author{
Huiqin Tu \\ School of Chinese Language and Literature \\ Central China Normal University \\ Wuhan, China
}

\begin{abstract}
Based on Dynamic Systems Theory, this study investigated the developmental trajectories of four Chinese EFL learners' oral proficiency and explored the dynamic correlation among complexity, accuracy and fluency used for measuring oral proficiency. The four EFL learner's speaking performance was traced and examined every two weeks over a twelve-week span. The data were collected by oral proficiency tests adapted from the oral tests of College English Test Band4(CET-4) in China and questionnaires on learning background. Instruments including moving min-max graph, scatter diagram and linear regression were applied for analyzing the data. It was found that the learners' oral complexity, accuracy and fluency showed nonlinear developmental patterns; there was negative correlation between fluency and accuracy in the early weeks while the correlation turned positive in a long term. The developmental patterns and dynamic correlations can provide insights into the interaction among the three variables contributing to oral proficiency in a dynamic system. The findings have valuable implications for theory construction and pedagogical practice of oral English.
\end{abstract}

Keywords-Dynamic Systems Theory (DST); speaking proficiency; dynamic development

\section{INTRODUCTION}

According to Dynamic Systems Theory (DST), EFL learners' language development is a dynamic and nonlinear process. Variables of a system are interdependent, inseparable and the behavior of a system is a result of interaction of all components. (De Bot et al, 2007)

EFL learners' oral proficiency is measured by three criteria -complexity, accuracy and fluency (CAF) in communication. (Skehan, 1996). For decades, more and more studies worldwide were carried out from different perspectives to explore correlations among the three variables. Larsen-Freeman (2006) observed five Chinese EFL female learners' complexity, fluency and accuracy of oral production during six months. She found that the five EFL learners showed different individual trajectories while their oral complexity, fluency and accuracy were on the rise with fluctuation overall. She also discovered individual experience and learning motivation impacted SL's development a lot. Vercellotti (2012) traced and recorded

*Sponsored by Humanity and Social Science Research Program of Education Bureau of Hubei Province (Grant NO.17G111) sixty-six EFL students' complexity accuracy and fluency of oral performance over three years span. She found all the students' developmental trajectories were similar and there were no distinctive differences among them or obvious changes in the same individual. In addition, she didn't find any negative correlation relation or positive correlation among complexity, accuracy and fluency in the study. Her findings differ absolutely from Larsen Freeman's, which may be due to their different observation intervals or frequencies. Cha Li (2014) conducted a dynamic research on English majors' CAF and concluded that EFL learners' oral proficiency developed with nonlinear trajectories and the correlations among CAF were not negative or positive all the time.

Despite the aforementioned studies pertaining to EFL learners' dynamic development of oral proficiency, a consensus on the developmental trajectories has not been reached. This empirical study aimed to provide another evidence for the research in this field and further enlightenment to EFL teaching by investigating the developmental trajectories of four Chinese EFL learners who were non-English majors coming from an application university. Their CFA of oral production were traced and recorded over twelve weeks to explore the dynamic correlation among the three variables. It is a diachronic study applying methods including audio recording, interviews, and questionnaires. It also aimed to find out the environmental factors impacting the participants' oral proficiency. To achieve those objectives, the following questions were discussed in the study:

- How do the groups of EFL learners' CAF of oral production develop?

- How does each individual EFL learner' CAF of oral production develop?

- Are there correlations among the EFL learners' oral proficiency in complexity, fluency and accuracy? What are the correlations?

\section{METHODOLOGY}

\section{A. Participants}

The participants in this study were four Chinese nonEnglish majors who came from one Chinese non- 
governmental application university. They were all freshmen when participating in the study and had learned English for about ten years. Two of the four participants were female and the other two were male.

\section{B. Instruments}

This diachronic study applied quantity methods as well as quality methods, which included tests, audio, questionnaires, audio-recalling and stimulating interviews.

The data-collection instruments used in this study were oral tests adapted from CET-4 oral test that was an authorized standardized test nationwide in China. The data of CAF collected from the tests were analyzed from the perspective of dynamic development.

This study used the methods of measuring CAF in terms of previous studies.

Linguists considered that complexity of output mainly concluded lexical complexity and syntactic complexity. This study applied syntactic complexity that was a more comprehensive criterion. It refers to the result of the number of clauses dividing the number of $\mathrm{T}$ sentences (Zhang Wenzhong 2001). One T-sentence includes all the clauses and embedded subordinate main sentences of non-clause structure.

The definition of Error-free clause (REFC) was applied for measuring accuracy by many previous studies. This study used the REFC referring to the result of the number of errorfree $\mathrm{C}$ unit dividing the number of all the $\mathrm{C}$ units.(Xu Qinfang 2002) One C unit is a sentence including a subject and an adjective, which was defined by Loban and Mehnert.

Fluency in this study was measured by SR referring to the number of all the syllables of words spoken out each minute. The specific calculating method is that the amount of a spoken sample's all syllables divides the total time. (Zhang Wenzhong 1999) The larger of SR is, the higher of fluency is. This method was used widely in linguistics due to its inclusion of language output and pause time.

In addition, a pre-questionnaire about participants' learning background was conducted before the whole empirical period. A post-questionnaire on oral performance and affective factors and an interview were carried out after each oral test.

\section{RESULT AND DISCUSSION}

\section{A. The Developmental Patterns of Group Oral Proficiency}

The trajectories of the participants' oral complexity, accuracy and fluency are illustrated in Fig.1. It's clear that students' developmental patterns of CAF are non-linear. The three variables' average data showing students' overall changes in CAF. Students' overall oral fluency was falling down while their complexity and accuracy were rising on the whole. The result indicates that EFL learners paid more attention to oral complexity and accuracy than fluency over a short-term span.
It's clear that the students' average scores of oral complexity and accuracy followed noticeable non-linear patterns. In the other words, the development of CAF didn't remain stable. Overall, the four students' scores of accuracy and fluency of the last oral test are relatively higher than those of the first test. While the initial score of complexity is a bit lower than that of the final test.

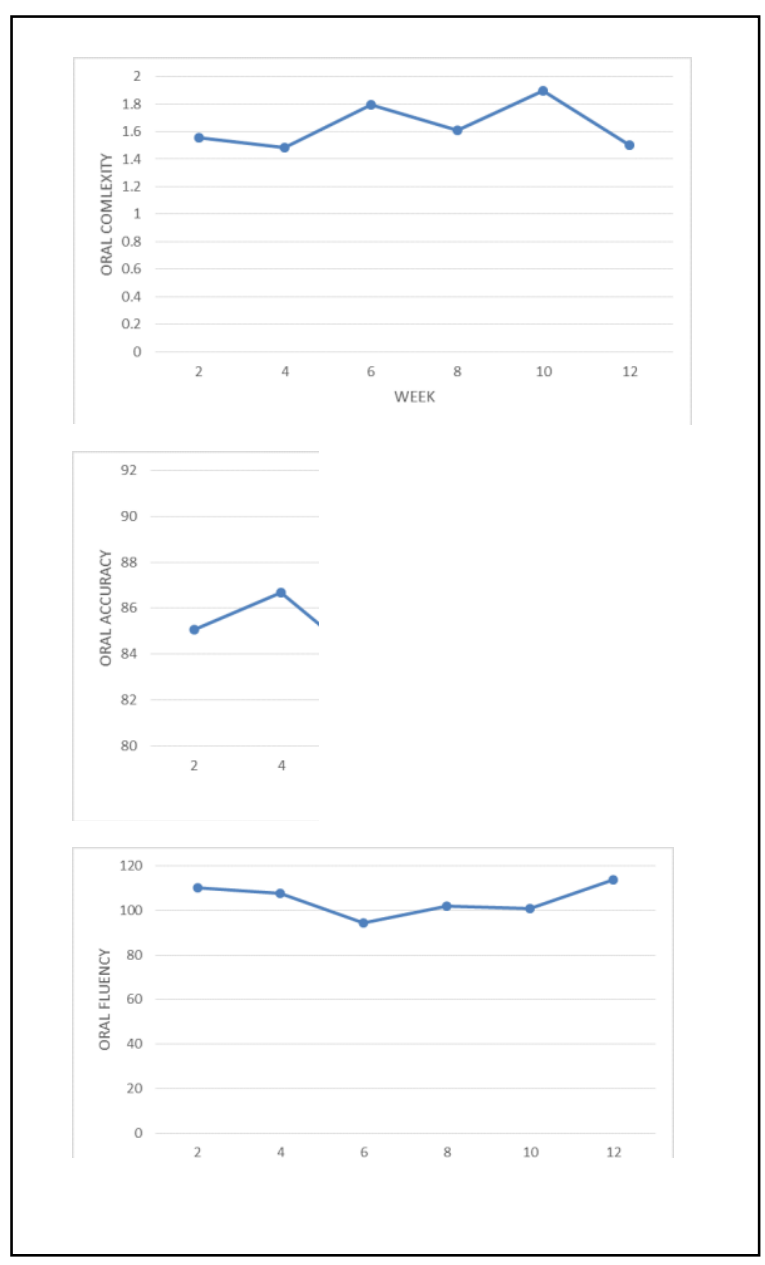

Fig. 1. Chages of average scores of the collective oral CAF.

From the "Fig. 1", it was found that the four students' average score of oral complexity was downward in general. And a sharp decline in complexity emerged in the last two weeks while there was a rise in it on the whole in the previous ten weeks. This result might be connected with the topic of the last oral test that was the same as the topic of the first test. According to the final post-interview, four participants mentioned that they felt more relaxed and more confident in expressing their ideas than the first time. Meanwhile they spoke faster and more fluently by using simpler and shorter sentences instead. Except for the result of the last test, the data of the previous tests show that the participants' complexity was upward due to their obtaining new knowledge and more drills on grammar during the span.

Among the three variables, there was a significant rise in accuracy over the period. And the average score was steadily ascending in the successive tests except for the third test. In 
that post-test interview, three students confessed that they didn't prepare very well as before because of their getting used to this kind of tests and slacking on English study. In addition, they thought they didn't accumulate enough vocabulary on this topic "your opinion on uncivilized travel". On the other hand, they wanted to finish the oral test as soon as possible. As a result, they didn't focus on using correct words or sentences. They also told the teacher that they felt sorry for their performance and would do it better next time with more serious attitude. Additionally, in the latter weeks of that semester, all the four students had prepared for CET-4 except for the oral part and did much practice on reading and listening. Therefore, the "Fig. 1" shows that participants' oral accuracy was upward, which proves their syntactic knowledge increased.

It was found that oral fluency did not improve during the whole period through the "Fig. 1" compared with the other two variables. According to post-interviews, all the four students said they spent less time learning English this semester especially during the first six weeks. Since the seventh week, they had increased the time spent in English reading and listening. It was attributed to the upcoming paper test of CET-4 in the nineteenth week of that semester. One of them had been preparing for IELTS besides CET-4. Therefore, most of them reduced the time of practicing oral English after classes.

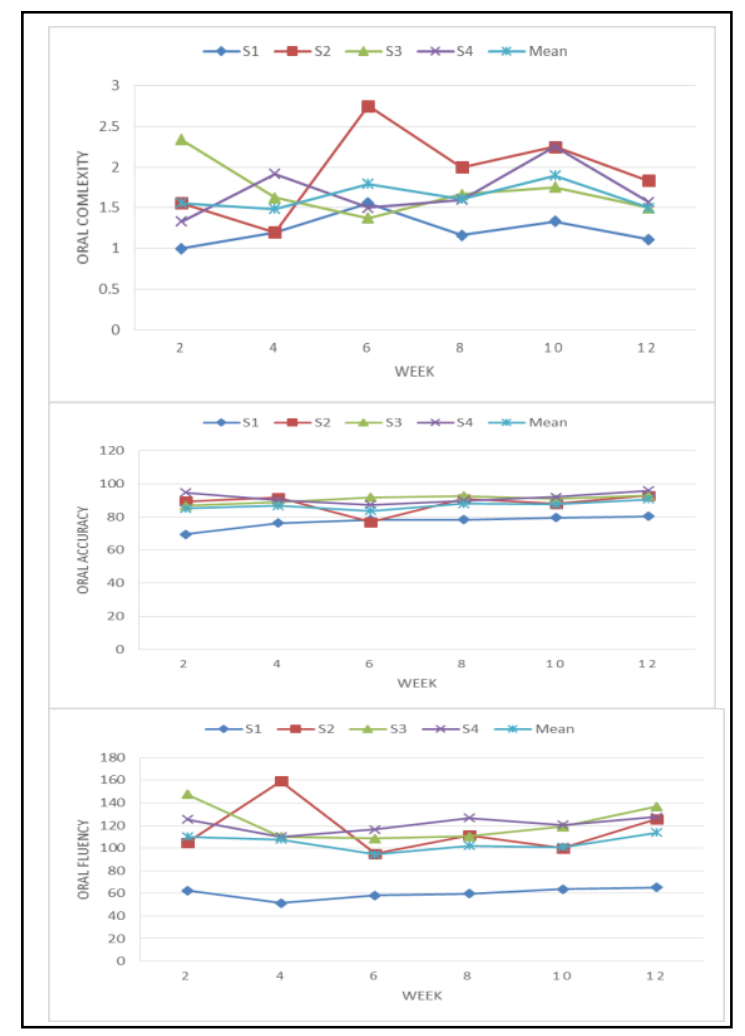

Fig. 2. Changes of individual oral CAF.

\section{B. The Developmental Patterns of Individual Oral Proficiency}

Similar to the trajectories of the group's oral CAF, the trajectories of individual CAF also demonstrated nonlinear development. But big differences existed between individuals' CAF and the group's CAF. Even distinction happened between individuals.

The "Fig. 2" shows that the trajectories of the four students' oral complexity are different from each other. S1 and S2 have similarity in developing changes after the first two tests, which are in accordance with the group's changes. With the students' further English learning and practice in college, three of them had got progress in oral complexity except for S3 whose initial value was the highest among the four students. S3 graduated from a famous local high school and had spent more time learning English relatively. Therefore she got stronger foundation in English, especially in grammar and reading on which more weight was put in Chinese high schools. However, she recalled she had used few time in English after entering college because she had a lot of work in students' journalist club and other new courses to take. Besides, she confessed she was not so serious and concentrated when taking the oral tests except for the first test. S2's oral complexity was at the top in the third time due to his familiarity of the topic and his memorizing some sentences samples for preparing CET-4 during that period. S2's score in National Entrance Examination for College of English in China and in the final English examination of the first semester in college showed that his English level was intermediate. That could explain his individual developmental trajectory of oral complexity was in accordance with the group's trajectory generally. In addition, S1's oral complexity got gradual progress over the span. For S1's English level was the lowest in the four students, which was known from the background questionnaire and class observation. However he had the strongest motivation of elevating English proficiency and spent much time in English study since entering college. As a result, there is no denying that oral complexity is associated with one's learning devotion and motivation.

As shown by "Fig. 2", four students' individual developmental trajectories of oral accuracy were also nonlinear and were of much similarity with the group's trajectory. It's obvious that S2's accuracy fell to the bottom in the sixth week. The result was opposite to that of the oral complexity of his oral performance in the third test. Besides, his individual developmental trend in oral accuracy was opposite to his individual developmental trend in oral complexity. That proved his complexity did not develop with accuracy together. Except for S2, all the other three students had quite similar trajectories in accuracy and all got a little advancement in oral accuracy compared with the initial time. The main reason might be more time and energy put in English reading listening and writing in the rest weeks of the semester. Those two aspects are closely related to grammar and vocabulary. 


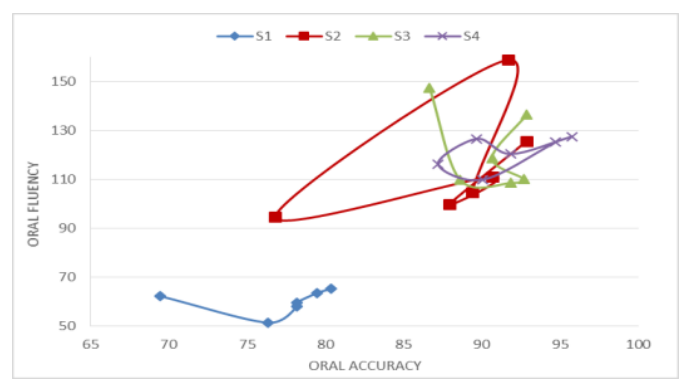

Fig. 3. Individual changes between oral fluency and oral accuracy.

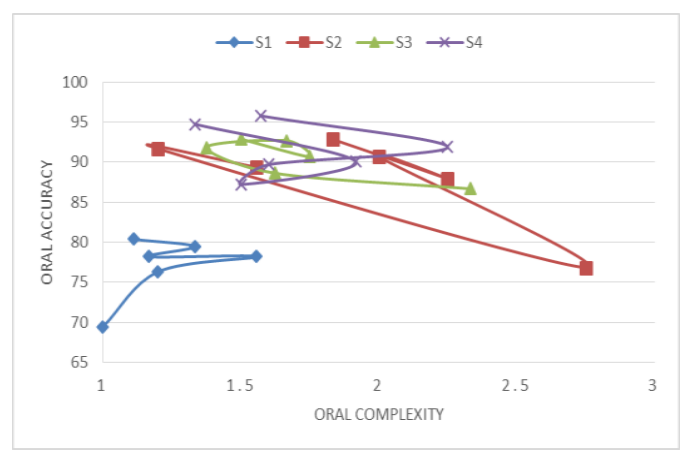

Fig. 4. Individual changes between oral fluency and oral complexity.

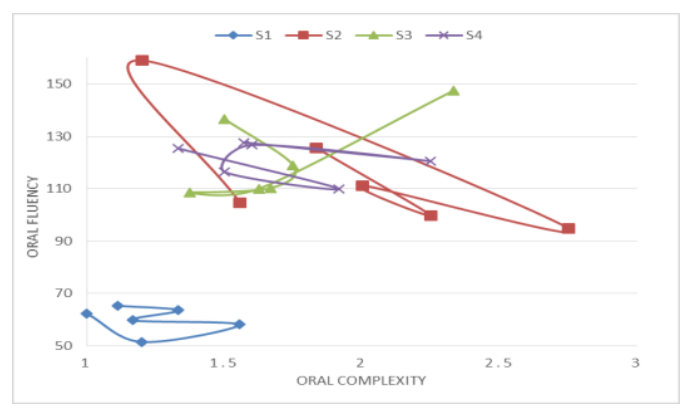

Fig. 5. Individual changes between oral accuracy and oral complexity.

As can be observed, the developmental trajectories of individual oral fluency were still nonlinear with little fluctuation. There was a slight upward trend in the fluency of S1, S2 and S4. Except that S3's fluency was downward compared with her initial value. It indicates all the four students got progress more or less except S3. In the last six weeks, S3 realized her slacking off and began to practice more in English. S2's oral fluency reached the peak in the second test. According to his recalling, he felt much relaxed that time thanks to his devotion to speaking drills including a similar topic. S1's oral fluency rose a little over the span. His initial value of fluency was much lower than the other students and so were the data in the rest weeks. His progress in fluency is not so obvious as that in the other two variables of CAF. It can be concluded that oral fluency's initial value impacts its developmental trajectory in a degree and it can't be changed easily in a short term. S4's oral fluency remained relatively higher among the four students. He mentioned not only would he take CET-4, also he would take IELTS including an oral test. So he spent more time practicing English speaking.

\section{The Correltions among $C A F$}

"Fig. 3", "Fig. 4" and "Fig. 5" the three scatter diagrams show the correlations among CAF through. They do not only demonstrate the non-linear developmental trajectories of the four students' oral proficiency but also demonstrate the diachronic development of the correlations among the three variables.

"Fig. 3" illustrates the four students' developmental trajectories of oral accuracy and fluency. As can be found, $\mathrm{S} 2$ and $\mathrm{S} 3$ underwent more significant change in $\mathrm{F}$ than in $\mathrm{A}$. $\mathrm{S} 1$ and $\mathrm{S} 4$ also experienced some changes in $\mathrm{F}$ and $\mathrm{A}$ while had less changes than the other two students in F. Those features prove the imbalance and variability in dynamic systems of second language development. There were negative correlations and positive correlations between $\mathrm{A}$ and $\mathrm{F}$ in different students at different phases. Fig.3 shows $\mathrm{S} 1$ is the only one whose trajectory doesn't entangle with the others' and is below the others', which indicates his A and F were much lower. On the other hand, his developmental track was generally rising at different phases with little fluctuation. It indicates the positive correlation between $\mathrm{A}$ and F. This result can't be separated with his much devotion to English study all the time. On the whole, during the early weeks, $\mathrm{A}$ and $\mathrm{F}$ demonstrated negative correlations while they showed positive correlations in the latter weeks.

It is found that individual changes of $\mathrm{F}$ and $\mathrm{C}$ are also nonlinear and complicated from Fig.4. Different individuals' $\mathrm{F}$ and $\mathrm{C}$ have different developing patterns. S2 and S3 underwent more significant changes in $\mathrm{F}$ and $\mathrm{C}$ among the four students. The negative correlation between $\mathrm{F}$ and $\mathrm{C}$ in $\mathrm{S} 2$ shows more distinctly in all the developing phases. It can be found that the correlations between oral $\mathrm{F}$ and $\mathrm{C}$ were negative in most phases of the four students. It indicates that oral complexity was closely associated with oral fluency in most phases. While the students used more complex sentences in speaking, they tended to pause or repeat more in constructing language.

"Fig. 5" illustrates that the positive correlations and negative correlations coexisted between $\mathrm{A}$ and $\mathrm{C}$ in different phases. S1's A and C were positively correlated to each other, which proved he had paid more attention to learning English and got some progress in overall aspects. S4's performance in these two aspects was also positively correlated because he had been preparing for the IELTS and had got improvement in English. S2 and S3 didn't trained themselves on purpose in English speaking during the span, so Fig.5 shows that while they put more weight on one aspect in the two their performance in the other one got worse, which implied they were lack of systematic training.

\section{CONCLUSION}

The study investigated the dynamic patterns of oral complexity, accuracy and fluency of oral proficiency. It also explored the correlations among the three variables from a Dynamic Systemic Theories (DST) perspective. The 
developmental trajectories reveal that the three variables demonstrate non-linear developmental patterns in group and individuals. It was found that the changes of the group's oral CAF were not so distinctive as those of individuals. Different individuals underwent different experiences that caused their distinctive changes at some phases. Significant changes may often be associated with EFL learners' learning attitude, motivation and devotion. This study also discovers that there are negative correlations as well as positive correlations among CAF. The negative correlations demonstrate more distinctively between $\mathrm{F}$ and $\mathrm{C}$. And there are negative correlations between $\mathrm{A}$ and $\mathrm{F}$ in a short term while the relationships may tend to be positive in a long term. That's to say, Chinese EFL learners would put more weight on oral accuracy than fluency in a short term while emphasize both $\mathrm{A}$ and $\mathrm{F}$ in a long term. Learners would pay less attention to F compared with the other two variables on the whole. Teachers need to encourage students to open their mouth without hesitation or being afraid of making mistakes. Besides, setting some oral tasks that are close to life and are of certain challenge to students is necessary, because the study found that students are more motivated when falling behind and feeling pressured.

\section{ACKNOWLEDGMENT}

I am grateful to Tu Huiqin who is my good friend and partner for her support and suggestions in carrying out the study. I am thankful to Prof. Xu Qiumei for her support and guidance before conducting the study. I am also grateful to my families for their support in life.

\section{REFERENCES}

[1] de Bot, K . "Introduction: Second language development as dynamic process, " The Modern Language Journal vol. 192, 2008, pp.166-178.

[2] Larsen -Freeman, D. "The emergence of complexity, fluency, and accuracy in the oral and written production of five Chinese learners of English," Applied Linguistics, vol. 27, 2006, pp. 590 -619.

[3] Polat, B. \& Kim, Y. "Dynamics of complexity and accuracy: a longitudinal casestudy of advanced untutored development," Applied Linguistics, vol. 35(2), 2014. pp.184-207.

[4] Skehan, P, A Cognitive Approach to Language Learning, Oxford: OUP, 1998.

[5] Vercellotti,M.L, Complexity, Accuracy, and Fluency as Properties of Language Performance. Pittsburgh: University of Pittsburgh, 2012.

[6] Verspoor, M., M. Schmid \& X. Xu, "A dynamic usage based perspective on L2 writing," Journal of Second Language Writing, vol. 21, 2012, pp.239-263.

[7] Han Yawen, "The influence of working memory on oral complexity,accuracy and fluency of Chineses EFL learners," Foreign Language Education vol.36(5),2015.9,pp.65-68

[8] Wang Haihua, Li Beibei, Xu Lin, "A dynamic case study of the development of Chinese English learners' Writing proficiency," Foreign Language Teaching and Research, vol. 47(1), 2015.1,pp.6980 . 